\title{
Achados fonoaudiológicos na hanseníase: considerações teóricas
}

\section{Speech-language findings on Hansen's disease: theoretical considerations}

\author{
Victor Gandra Quintas 1 , Patrícia Vieira Salles ${ }^{2}$, Virgínia Cátia Costa ${ }^{3}$, Elisa Andrade de Alvarenga ${ }^{4}$, \\ Izabel Cristina Campolina Miranda ${ }^{5}$, Tiago Mendonça Attoni ${ }^{6}$
}

\begin{abstract}
RESUMO
A hanseníase é uma doença que tem altos níveis de incidência no Brasil. De origem bacteriana crônica, com alta infectividade e baixa patogenicidade, tem como hospedeiro primário o homem e como agente etiológico o Mycobacterium leprae. O bacilo de Hansen, como também é conhecido o agente, se acumula principalmente na pele, nos nervos periféricos e pares cranianos, levando a diversas lesões cutâneas, também à perda da condução neural e, consequentemente, a severas alterações anatômicas e funcionais nas extremidades do corpo, como membros e região orofacial. De acordo com estas premissas, foi realizada uma revisão da literatura com intuito de mostrar a fisiopatologia da doença e sua classificação de acordo com as suas manifestações. Desta forma, a literatura, por intermédio de alguns estudos, mostrou que esta doença pode provocar alterações que comprometem significativamente a voz, a audição, os órgãos fonoarticulatórios e as funções estomatognáticas, tornando-se assim, de grande relevância à Fonoaudiologia.
\end{abstract}

Descritores: Hanseníase/complicações; Sensibilidade térmica; Nervos cranianos; Sistema estomatognático; Perda auditiva; Qualidade da voz

\section{INTRODUÇÃO}

A hanseníase é uma doença bacteriana crônica, de alta infectividade e baixa patogenicidade, na qual o agente etiológico é o Mycobacterium leprae, também chamado de bacilo de Hansen. Um parasita intracelular obrigatório que se acumula principalmente na pele, nos nervos periféricos e pares cranianos, levando a diversas lesões cutâneas, à perda da condução neural e, consequentemente, a severas alterações anatômicas e funcionais nas extremidades do corpo, membros e região orofacial ${ }^{(1-9)}$.

Trabalho de conclusão de curso realizado na Pontifícia Universidade Católica de Minas Gerais - PUC-Minas - Belo Horizonte (MG), Brasil.

(1) Pós-graduando (Mestrado) em Distúrbios da Comunicação Humana pela Universidade Federal de Santa Maria - UFSM - Santa Maria (RS), Brasil.

(2) Mestre, Professora do Curso de Fonoaudiologia da Pontifícia Universidade Católica de Minas Gerais - PUC-Minas - Belo Horizonte (MG), Brasil.

(3) Acadêmica do Curso de Fonoaudiologia da Pontifícia Universidade Católica de Minas Gerais - PUC-Minas - Belo Horizonte (MG), Brasil.

(4) Acadêmica do Curso de Fonoaudiologia da Pontifícia Universidade Católica de Minas Gerais - PUC-Minas - Belo Horizonte (MG), Brasil.

(5) Doutora, Professora do Curso de Fonoaudiologia da Pontifícia Universidade Católica de Minas Gerais - PUC-Minas - Belo Horizonte (MG), Brasil. (6) Pós-graduando (Mestrado) em Distúrbios da Comunicação Humana pela Universidade Federal de Santa Maria - UFSM - Santa Maria (RS), Brasil. Endereço para correspondência: Victor Gandra Quintas. Av. Doutor Guilhermino de Oliveira, 466, Bairro Novo Eldorado, Contagem (MG), Brasil, CEP: 32341-290. E-mail: fgo.victorquintas@yahoo.com.br

Recebido em: 16/4/2009; Aceito em: 21/8/2009
A hanseníase representa um importante problema de saúde pública no panorama nacional, uma vez que figura em lugar destacado entre as morbidades e condições que originam incapacidades físicas ${ }^{(1-9)}$.

Embora a doença ocorra em todas as classes sociais, há uma incidência significativamente maior nas populações de nível socioeconômico inferior, nas quais também há um baixo nível de educação, cultura e nutrição ${ }^{(10-11)}$.

Assim, a hanseníase exige medidas de controle que devem ser compartilhadas por todos os profissionais de saúde em todos os níveis de atenção $0^{(1,10-11)}$.

O objetivo deste estudo foi reunir trabalhos com base na fisiopatologia da hanseníase, descrevendo as manifestações que envolvem a área da Fonoaudiologia.

Para tanto foi realizada uma busca pela literatura científica publicada até novembro de 2007, nas bases de dados MedLine, Web of Science, SciELO, LILACS. Foram incluídos estudos que fossem relevantes ao tema proposto.

\section{REVISÃO DA LITERATURA}

Segundo as estatísticas, o Brasil é o país com maior incidência da doença em todo o continente americano e o terceiro em todo o mundo. Nos últimos seis anos, a média de novos casos em menores de 15 anos foi de 8,4\% em relação ao número total de casos detectados no Brasil, que é de 47.400. 
Isso porque essas notificações indicam que há adultos sem o diagnóstico da doença, convivendo e transmitindo a hanseníase para crianças e adolescentes, geralmente da mesma família ${ }^{(10-11)}$.

O Estado de Minas Gerais, ao final de 2006, registrou 2.368 doentes em tratamento, correspondendo a 1,2 casos para cada 10 mil habitantes; taxa que em 2005 foi de 1,5 casos para cada 10.000 habitantes ${ }^{(10-11)}$.

\section{Contágio e classificação}

A via inicial de contágio é respiratória ou gastrointestinal. Os bacilos isolados nas secreções nasais ressecadas mantêm alguma viabilidade por até sete dias e uma viabilidade um pouco maior em condições de umidade ${ }^{(1-5)}$.

As vias aéreas superiores constituem a principal porta de entrada e de eliminação do bacilo. A pele erodida pode permitir infecção e as secreções orgânicas como leite, suor, esperma e secreção vaginal podem eliminar bacilos, mas não possuindo importância na disseminação da infecção. Desta forma, a transmissão da doença de uma mãe infectada não-tratada para o lactente deve ser sempre considerada ${ }^{(1-4)}$.

A hanseníase se apresenta de duas formas distintas, a paucibacilar (PB), que gera menos de cinco lesões de pele e acomete um tronco nervoso; e a multibacilar (MB), que gera cinco ou mais lesões de pele e acomete mais de um tronco nervoso ${ }^{(1-4)}$.

Clinicamente, a hanseníase pode manifestar-se como tipo I ou Reação Reversa, caracterizada por novas lesões dermatológicas (manchas ou placas), alterações de cor além edema nas lesões antigas, bem como dor ou espessamento dos nervos (neurites). Já o tipo II ou Eritema Nodoso Hansênico, manifesta-se através de nódulos vermelhos dolorosos, febre, dores articulares, neuralgia e espessamento dos nervos, assim como mal estar generalizado ${ }^{(2,4)}$.

São descritas na literatura ${ }^{(2,4,12)}$ outras formas de hanseníase a partir de manifestações clínicas diferentes, porém as mais citadas são:

- Hanseníase Indeterminada (HI): caracterizada pelo aparecimento de manchas hipocrônicas com alteração de sensibilidade ou áreas de hipoanestesia na pele. O número de lesões é pequeno e estas podem se localizar em qualquer área. Geralmente, a sensibilidade térmica está alterada. A HI é considerada a primeira manifestação clínica da hanseníase e, após um período de tempo que varia de meses a anos, ocorre a evolução da doença para cura ou para outra forma clínica. O período de incubação dura em média de dois a cinco anos ${ }^{(4)}$.

- Hanseníase Tuberculóide (HT): apresenta lesões bem delimitadas, também em número reduzido, com distribuição assimétrica e anestésica ao longo da pele. Ocorrem lesões em placas ou anulares com bordas papulosas e áreas eritematosas. Existem as variedades infantis que se manifestam em crianças conviventes com portadores de formas bacilíferas, com localização principalmente na face. Também há a forma neural pura, que não apresenta lesões cutâneas, mas há espessamento do tronco nervoso, causando dano neural precoce e grave, principalmente quando atinge nervos sensitivo-motores. Há possibilidade de cura espontânea da HT, mas a orientação é o tratamento, pois reduz o tempo de evolução e risco de dano neural ${ }^{(4,13)}$. - Hanseníase Virchowiana (HV): é a forma multibacilar da doença e manifesta-se nos indivíduos que apresentam imunidade celular deprimida para o bacilo. A HV pode evoluir da forma indeterminada ou manifestar-se como tal desde o início. A evolução crônica é caracterizada por infiltração progressiva e difusa da pele, mucosas das vias aéreas superiores, olhos, testículos, linfonodos, fígado, baço e nervos como o nervo facial (VII par craniano), nervo trigêmio ( $\mathrm{V}$ par craniano), nervo ulnar, nervo mediano, nervo radial, nervo fibular comum e nervo tibial ${ }^{(1,3-4,14)}$.

Na pele, a HV manifesta-se como pápulas, nódulos e máculas, sendo que a infiltração é difusa e mais acentuada na face e nos membros. Há rarefação dos pelos dos supercílios, cílios e membros. A infiltração da face também inclui os pavilhões auriculares. O comprometimento nervoso ocorre nos ramúsculos da pele, na inervação vascular e nos troncos nervosos, que vão apresentar deficiências funcionais e sequelas tardias. Como sinal precoce da HV tem a obstrução nasal, rinorréia serossanguinolenta e edema de membros inferiores ${ }^{(4,15)}$.

- Hanseníase Dimorfa (HD): caracteriza-se por instabilidade imunológica, causando grande variação em suas manifestações clínicas, seja na pele, nervos ou de forma sistêmica. As lesões da pele mostram aspectos de HV e HT e pode ter predominância ora de um tipo ora de outro. Estas lesões são eritematosas, manchas hipocrônicas com bordas ferruginosas. Quando numerosas são chamadas de lesões em renda ou queijo suíço. As alterações faciais apresentadas são elementos sugestivos desta forma clínica que pode levar a incapacidades físicas ${ }^{(1,3-4,16)}$.

\section{Diagnóstico e manifestações}

O diagnóstico da doença é clínico-epidemiológico e laboratorial; porém, nas regiões em que a hanseníase é endêmica, quando não se dispõe de recursos laboratoriais, o diagnóstico é apenas clínico ${ }^{(1,3-4,17)}$

O tratamento é feito com quimioterapia específica, supressão dos surtos reacionais, prevenção das incapacidades físicas, reabilitação física e psicossocial, que devem ser desenvolvidas em serviços de saúde da rede pública ou particular, com notificação de casos à autoridade sanitária competente ${ }^{(5)}$.

Deve-se levar em conta no esquema terapêutico toda a história clínica do paciente, com especial atenção para alergias a medicamentos, interação de drogas e doenças associadas. As drogas usadas, segundo órgão especializados ${ }^{(9-10)}$, são a rimfampicina (bactericida padrão), dapsona e clofazimina. Em alguns casos mais graves com reações do tipo 2 ou Eritema Nodoso são usados outras drogas associadas. O tratamento tem duração de 12 meses. Os casos multibacilares avançados, com infiltração exuberante da pele e que apresentam pouca melhora com as 12 doses, deverão receber 24 doses em até 36 meses $^{(1-4,18)}$.

A hanseníase, portanto, pode gerar comprometimentos funcionais como perda da sensibilidade térmica, mãos em garra devido à atrofia muscular, perda das falanges dos dedos das mãos e dos pés, desabamento da cartilagem nasal e do pavilhão auricular. Pode afetar os nervos cranianos e apresentar lesões 
nas cavidades oral e nasal, o que gera alterações oromiofaciais em diferentes aspectos morfofuncionais e com graus variados de comprometimento ${ }^{(5,19)}$.

Estas alterações podem comprometer significativamente a voz, a audição e as funções estomatognáticas, sendo necessária a intervenção fonoaudiológica para a estimulação das habilidades comunicativas e alimentares ${ }^{(5,14)}$.

Os pares cranianos acometidos são: I (olfatório), V (trigêmio), VII (facial), VIII (vestibulococlear), IX (glossofaríngeo), X (vago), XI (acessório) e XII (hipoglosso). Os nervos responsáveis pela visão e pela movimentação ocular, respectivamente II (óptico) e III, IV, VI (oculomotor, troclear e abducente) também são afetados; porém, vamos nos ater aos que foram citados anteriormente pelo fato de terem maior implicação na área fonoaudiológica ${ }^{(5,12-13)}$.

A lesão do nervo olfatório leva à perda ou diminuição do olfato, que tem grande inter-relação com o paladar, pode causar alteração sensitiva na fase oral da deglutição ${ }^{(5,12,14)}$.

Quando ocorre acometimento do nervo trigêmeo, há diminuição de força da musculatura elevadora da mandíbula, ocasionando dificuldade mastigatória e, consequentemente, alterações na estrutura muscular e óssea do complexo crâniofacial, como disfunção da articulação temporomandibular (ATM), comprometimento das bases osteodentárias, do periodonto e assimetria facial. Além disso, há perda da sensibilidade facial e da sensibilidade geral nos dois terços anteriores da língua, que ajuda a dificultar o preparo do bolo alimentar. Podem, ainda, ocorrer alterações auditivas, pois o músculo tensor do tímpano é inervado pelo trigêmeo ${ }^{(5,8,17-18)}$.

O nervo facial afetado leva à perda ou diminuição da mímica facial, causando uma paralisia ou paresia, dificultando a expressão facial e comunicativa. Há, também, perda da gustação nos dois terços anteriores da língua, dificuldade de audição por afetar o músculo estapédio e alteração na função do músculo bucinador ${ }^{(5,12-14,16-19)}$.

O nervo vestibulococlear quando afetado, gera alteração do equilíbrio, com sintomas como vertigens, tonturas e/ou náuseas. Além disso, pode ocorrer perda auditiva neurossensorial, além de zumbido e dificuldades de compreensão da fala, principalmente em ambientes ruidosos ${ }^{(20-21)}$.

A lesão do nervo glossofaríngeo acarretará transtornos da deglutição nas fases oral e faríngea, pois compromete a sensibilidade no terço posterior da língua e a sensibilidade da faringe. Além disso, pode afetar a ressonância devido à alteração na movimentação do véu palatino ${ }^{(5,12,22)}$.

O nervo vago é responsável pela inervação das pregas vocais e da musculatura intrínseca da laringe. Sua lesão pode afetar a produção e qualidade da voz, pois compromete a coaptação glótica. Também pode agravar um quadro de disfagia, pois este nervo craniano participa da formação do plexo farín-

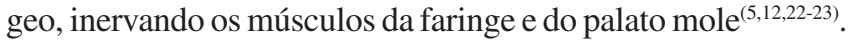

A lesão do nervo acessório, que é responsável pela inervação dos músculos esternocleidomastóideo e trapézio, acarretará prejuízo na musculatura cervical de forma motora e sensitiva $^{(5,8,14)}$.

O nervo hipoglosso é responsável pela movimentação da língua e sua lesão pode levar à disfagia e a alterações da fala $^{(16,22,24)}$.
Além do comprometimento dos nervos cranianos, os indivíduos portadores de hanseníase podem apresentar alteração da mucosa nasal, na fase inicial da doença e comprometimento da mucosa oral independente da presença de lesões aparentes $^{(12,16,25-28)}$

A sequência de alterações que surge na mucosa oral é semelhante à encontrada na pele, sendo definida por estágios de invasão, proliferação e resolução e ocorre na grande maioria dos pacientes portadores da forma lepromatosa em atividade e nos cinco primeiros anos de desenvolvimento da doença ${ }^{(16,26-29)}$.

A hanseníase se aloja principalmente na gengiva, porção anterior da maxila, palato duro e mole, úvula e língua. Porém, nenhum tipo de lesão bucal é patognomônica para hanseníase. Estas lesões geralmente apresentam-se como nódulos assintomáticos que necrosam e ulceram, contudo, o envolvimento lingual pode ser sintomático ${ }^{(25-27)}$.

Vale ressaltar que as alterações de mucosa nasal e oral deverão ser avaliadas e tratadas respectivamente pelo otorrinolaringologista e pelo dentista, mas cabe ao fonoaudiólogo saber identificar tais alterações e encaminhar o paciente para estes profissionais ${ }^{(16,25,28)}$.

\section{DISCUSSÃO}

Na literatura, há consenso de que o principal meio de contágio da doença são as vias aéreas superiores e a contaminação ocorre pelo contato físico com as feridas ocasionadas pela hanseníase ${ }^{(1-2,9,16)}$.

Existem discordâncias devido às várias alterações existentes, que só poderiam ser classificadas como outra forma de hanseníase, pois as manifestações clínicas podem extrapolar as descritas na literatura ${ }^{(6,16)}$.

O tratamento farmacológico é o mesmo descrito pela maioria dos autores, visto que a quimioterapia oferecida pelos postos de saúde é padrão da $\mathrm{OMS}^{(1,10)}$. Porém, há relatos do uso de talidomida e outros medicamentos como analgésicos ou anti-inflamatórios não hormonais (AINES), corticóides, pentoxifilina e prednisona em casos de reações do tipo 2 ou eritema nodoso. A talidomida está proibida para uso em mulheres na idade fértil ${ }^{(1)}$.

Quanto aos pares cranianos comprometidos, há concenso quanto às respectivas funções alteradas, destacando-se os nervos: olfatório, trigêmio, facial, vestibulococlear, glossofaríngeo, vago, acessório e hipoglosso, que são de interesse direto do fonoaudiólogo ${ }^{(2,5,13)}$.

Não foi encontrada uma terapia específica para esta doença; entretanto, é importante descrever as prováveis intervenções nas diversas manifestações, já que estas são bastante semelhantes às encontradas em outras doenças. Desta forma, o fonoaudiólogo deve observar alguns fatores importantes, aplicando o seu conhecimento nas diversas áreas, como no caso de respiradores orais, especificamente na perda ou diminuição de olfato e gustação, englobando a estimulação destes sentidos por meio de alimentos de diversos sabores, seja em terapia direta ou indireta ${ }^{(14,24)}$.

Quanto à alimentação, é provável que o melhor meio seja fazer com que o indivíduo veja o alimento e sinta o cheiro, permitindo ao cérebro disparar o comando para as glândulas 
salivares iniciarem a produção de saliva, pré-ativando a cavidade oral. Entende-se, então, que o olfato tem grande importância para os processos de mastigação e deglutição, o que mostra que a estimulação deste sentido pode ser apresentada de forma intensa, antes de iniciar a terapia direta da deglutição ${ }^{(14,24)}$.

O fonoaudiólogo pode utilizar da terapia indireta, que é sem o alimento, com deglutição induzida por estímulos táteis, térmicos e gustativos, que podem ser eficazes nesta doença. Já a terapia direta, com a introdução do alimento, seria de mais valia utilizando-se também de manobras facilitadoras da deglutição e posturas adequadas. Acredita-se que com estes cuidados haja melhora no quadro ${ }^{(14,24)}$.

Quando houver acometimento da sensibilidade geral da cavidade oral e especificamente da língua, estas também podem ser estimuladas na terapia fonoaudiológica, podendo propiciar um resultado satisfatório, visto que em pacientes com outros distúrbios apresentam resultados positivos neste tipo de intervenção ${ }^{(14,24)}$.

Ao abordar a mastigação, o terapeuta poderá utilizar, de acordo com os seus conhecimentos, a terapia direta com alimento sólido, sendo esta mais eficaz, pois é uma atividade a ser realizada pelo paciente durante todo o dia. É importante ressaltar que se o paciente estiver com um quadro de disfagia grave, a terapia sempre começará de forma indireta, até que haja segurança suficiente para introdução de alimento, ou seja, para o início da terapia direta ${ }^{(14,24)}$.

Após a avaliação fonoaudiológica específica das fases oral e faríngea da deglutição, nas três consistências alimentares com volume seguro, pode-se solicitar uma videofluoroscopia como exame complementar, de forma que a fase esofágica seja avaliada. Acredita-se que isso ajudará a traçar um plano terapêutico adequado às funções alteradas com o objetivo de estimular tal função ${ }^{(14,24)}$.

É provável que as manifestações decorrentes de afecção do nervo facial também tragam alterações de fala e deglutição; sendo assim, a avaliação e o tratamento fonoaudiológico podem ser necessários, levando o indivíduo a manter a musculatura envolvida em constante atividade, preparando-a para a regeneração de forma controlada e simétrica, e não somente a musculatura isolada da função ${ }^{(14)}$.
A atuação do fonoaudiólogo no caso de perda auditiva será de orientação, protetização e reabilitação. Se houver vertigens e tonturas, existe especificamente a reabilitação vestibular, que poderá trazer excelentes resultados, melhorando significativamente a qualidade de vida do paciente ${ }^{(18,20)}$.

A terapia vocal nestes pacientes é semelhante à terapia de paralisia ou paresia de prega vocal de outra origem. Em muitos casos, a terapia não será satisfatória para retomada de fonação, mas pode ser eficiente para garantir deglutição segura, visto que a elevação da laringe e o fechamento da glote contribuem para proteção das vias aéreas superiores ${ }^{(23)}$.

Todas essas alterações relatadas e seus respectivos processos terapêuticos estão em acordo com a maior parte da literatura pesquisada e são, também, semelhantes a muitas outras doenças de base. Assim, fica evidenciada a necessidade de uma avaliação específica para saber o grau de acometimento e o quanto ele afeta a vida do indivíduo, contribuindo para traçar um plano terapêutico condizente ${ }^{(16,25)}$.

\section{COMENTÁRIOS FINAIS}

Diante das informações obtidas na literatura, vimos que a doença gera danos aos pares cranianos e aos nervos periféricos. A audição, a voz e as funções do sistema estomatognático, bem como a cavidade nasal e oral, principalmente mucosa jugal, língua e palato mole, podem estar severamente comprometidas, tornando-se assim de grande relevância à Fonoaudiologia

Desta forma, tomando conhecimento das alterações fonoaudiológicas decorrentes da hanseníase, o profissional pode contribuir significativamente para a qualidade de vida dos indivíduos hansenianos, seja por meio de ações preventivas e/ou de reabilitação das diferentes seqüelas, que acarretam prejuízos funcionais ao paciente e maiores gastos para a instituição.

No entanto, não são encontrados muitos artigos e pesquisas referentes à atuação da Fonoaudiologia nesta doença, o que demonstra a importância do incentivo a novas pesquisas relacionadas. Afinal, o Brasil ainda é um dos países do mundo com maior índice desta doença.

\begin{abstract}
Hansen's disease is a malady that has high incidence levels in Brazil. It has a chronic bacterial origin, with high infectivity and low pathogenicity, having the man as its primary host, and the Mycobacterium leprae as its etiological agent. The Hansen's bacillus, as it is known, accumulates mainly in the skin, the peripheral nerves and the cranial nerves pairs, causing many skin lesions, as well as loss of neural conduction and, consequently, severe anatomical and functional changes in the ends of the body, such as members and the orofacial region. Based on these premisses, it was carried out a literature review in order to show the pathophysiology of the disease and its classification according to its manifestations. The literature review showed, through some studies, that the disease might cause alterations that significantly compromise the voice, the hearing, the phonoarticulatory organs, and the stomatognathic functions, thus becoming relevant to be studied in Speech-Language Pathology.
\end{abstract}

Keywords: Leprosy/complications; Temperature sense; Cranial nerves; Stomatognathic system; Hearing loss; Voice quality 


\section{REFERÊNCIAS}

1. Talhari S, Neves RG. Dermatologia tropical - Hanseníase. 3a ed. Manaus: Tropical; 1997.

2. Landais C, Graffin B, Leyral G, Boyé T, Carli P, Carsuzaa F. Syndrome des mains boudinées révélant une lèpre lépromateuse Lepromatous leprosy revealed by a swollen hands syndrome. Méd Mal Infect. 2009;39(1):55-6.

3. Lima ES, Roland Ide A, Maroja Mde F, Marcon JL. Vitamin A and lipid peroxidation in patients with different forms of leprosy. Rev Inst Med Trop São Paulo. 2007;49(4):211-4.

4. Araújo MG. Hanseníase no Brasil. Rev Soc Bras Med Trop. 2003;36(3):373-82.

5. Kumar S, Alexander M, Gnanamuthu C. Cranial nerve involvement in patients with leprous neuropathy. Neurol India. 2006;54(3):283-5.

6. Souza FC, Marcos EV, Ura S, Opromolla PA, Nogueira ME. Estudo comparativo entre reação de Mitsuda e antígenos leucocitários humanos em pacientes hansenianos. Rev Soc Bras Med Trop. 2007;40(2):188-91.

7. Gourie-Devi M. Cranial neuropathy in patients with leprosy. Neurol Índia. 2006;54(3):248-9.

8. Pereira HL, Ribeiro SL, Cinonelli RM, Fernandes AR. Avaliação por imagem do comprometimento osteoarticular e de nervos periféricos na hanseníase. Rev Bras Reumatol. 2006;46(Supl 1):30-5.

9. Leboeuf MA, Grossi MA. Hanseníase: um problema de saúde pública. Belo Horizonte: Secretaria de Estado da Saúde de Minas Gerais; 2004.

10. World Health Organization. Leprosy. Global Situation. Weekly Epidemiol Record [Internet]. 2002 [cited 2007 Sep 18]; 77(1):1-8. Available from: http://www.who.int/lep/resources/wer7701.pdf

11. Souza AD, el-Azhary RA, Foss NT. Management of chronic diseases: an overview of the Brazilian governmental leprosy program. Int $\mathrm{J}$ Dermatol. 2009;48(2):109-16.

12. Villar VM, Furia CL, Mello Junior EJ. Disfagia orofaríngea em indivíduos portadores de hanseníase. Rev CEFAC. 2004;6(2):151-7.

13. van Brakel WH, Nicholls PG, Wilder-Smith EP, Das L, Barkataki P, Lockwood DN ET al. Early Diagnosis of Neuropathy in LeprosyComparing Diagnostic Tests in a Large Prospective Study (the INFIR Cohort Study). PLoS Negl Trop Dis. 2008;2(4):e212.

14. Jacobi JS, Levy DS, Silva LM. Disfagia: avaliação e tratamento. Rio de Janeiro: Revinter; 2003.
15. Marchesan IQ. Fundamentos em fonoaudiologia: aspectos clínicos da motricidade oral. Rio de Janeiro, Guanabara Koogan; 1998. Avaliação e terapia dos problemas da respiração; p. 23-36.

16. Bhat R, Sharma VK, Deka RC. Otorhinolaryngologic manifestations of leprosy. Int J Dermatol. 2007;46(6):600-6.

17. Reichart PA, Srisuwan S, Metah D. Lesions of the facial and trigeminal nerve in leprosy. An evaluation of 43 cases. Int J Oral Sug. 1982;11(1):14-20.

18. Barros JN de, Melo AM, Gomes IC. Paralisia facial periférica prognósticos. Rev CEFAC. 2004;6(2):184-8.

19. Behlau M, Gasparini G. Classification manual for voice disorders-I CMVD-I. Rev Soc Bras Fonoaudiol. 2007;12(1):72-5.

20. Frota S. Audiologia. 2a ed. Rio de Janeiro: Guanabara Koogan; 2003.

21. Herdman SJ. Reabilitação vestibular. 2a ed. Barueri (SP): Manole; 2002.

22. Dhar S, Sharma VK, Kaur S. Facial, glossopharyngeal, vagus and hypoglossal nerve palsy in case of lepromatous leprosy. Indian J Dermatol. 1993;65(3):333-6.

23. Behlau M. Voz: o livro do especialista. Vol. 2. Rio de Janeiro: Revinter; 2006.

24. Marchesan IQ. Aspectos clínicos da motricidade oral. Rio de Janeiro: Guanabara Koogan; 1998.

25. Mocelin M, Repka J, Stahlke LG, Catana GS, Stahlke PS, Yosida LY, Cabvera PF. Avaliação da microbiota bacteriana nasal hansenianos. Rev Bras Otorrinolaringol. 1998;64(1):26-31.

26. Abreu MA, Michalany NS, Weckx LL, Pimentel DR, Hirata CH, Alchorne MM. A mucosa oral na hanseníase: um estudo clínico e histopatológico. Rev Bras Otorrinolaringol. 2006;72(3):312-6.

27. D'Abreu PC, Durães SM, Estrela RR, Baltazar MC, Rochael MC. Hanseníase virchowiana diagnosticada através de exame histopatológico de lesão oral em paciente com pênfigo foliáceo. An Bras Dermatol. 2000;75(3):339-46.

28. Santos GG, Marcucci G, Marchese LM, Guimarães Jr J. Aspectos estomatológicos das lesões específicas e não-específicas em pacientes portadores da moléstia de Hansen. Pesqui Odontol Bras. 2000;14(3):268-72.

29. Russo MP, Corrêa CT, Martins MA, Martins MD. Aspectos da doença de Hansen relevantes para o cirurgião-dentista: revisão de literatura. Rev Odonto Ciência. 2005;20(48):126-31. 